\title{
PENGUJIAN DAN KALIBRASI ALAT KESEHATAN PADA ELECTROCARDIOGRAPH
}

\author{
Erna Kusuma Wati ${ }^{* 1}$, Syalma Nova Herdenita ${ }^{2}$ \\ Program Studi Teknik Fisika, Universitas Nasional \\ ernakusuma.w@gmail.com ${ }^{* 1}$, syalmanovaherdenita@gmail.com ${ }^{2}$
}

Submitted March 10, 2021; Revised August 2, 2021; Accepted August 4, 2021

\begin{abstract}
Abstrak
Electrocardiograph (ECG) merupakan instrument medis yang mampu mengukur aktivitas listrik yang dihasilkan oleh jantung untuk mendeteksi kelainan pada organ tersebut. Sehingga sangatlah penting untuk memperoleh hasil yang akurat agar dalam menentukan diagnosa penyakit seorang pasien. Tidak presisinya peralatan EKG akan menyebabkan hasil perekaman aktivitas kelistrikan jantung yang tidak akurat. Dengan demikian perlu dilakukan pengujian secara berkala pada alat ECG dan dilakukan kalibrasi. Dalam penelitian ini akan dilakukan pengujian pada alat Electrocardiograph (ECG) dengan merk GE, Tipe Mac 600. Metode yang digunakan adalah metode perbandingan langsung dengan Electrocardiograph Simulator. Hasil pengujian mendapatkan nilai kalibrasi level tegangan dengan toleransi $5 \%$ dengan nilai 5,10 , dan $20 \mathrm{~mm} / \mathrm{mV}$. Nilai pada kalibrasi laju rekaman memiliki toleransi $5 \%$ yaitu sebesar $99 \mathrm{~mm}$ untuk 8 siklus dan $98.5 \mathrm{~mm}$ untuk 4 siklus. Sedangkan pada kalibrasi sinyal ECG didapat hasil pengukuran sebesar $10 \mathrm{~mm}$ dan masih dalam batas toleransi $5 \%$, dan hasil kalibrasi sinyal sinusoida $20 \mathrm{~mm}$ dan masih dalam batas toleransi $10 \%$.
\end{abstract}

Kata Kunci : ECG, kalibrasi, nilai toleransi

\begin{abstract}
An electrocardiograph (ECG) is a medical instrument that can detect abnormalities by measuring the electrical activity generated by the heart as the heart contracts. So it is crucial to obtain accurate results in determining the diagnosis of a patient's disease. The imprecision of the ECG equipment will result in an inaccurate recording of the heart's electrical activity. Thus it is necessary to test the ECG tool and perform calibration periodically. In this research, testing will be carried out on an Electrocardiograph (ECG) device with the GE brand, Type Mac 600. The method used is the direct comparison method with the Electrocardiograph Simulator. The test results get a voltage level calibration value with a tolerance of $5 \%$ with a value of 5.10 and $20 \mathrm{~mm} / \mathrm{mV}$. The recording rate calibration value has a tolerance of $5 \%$, which is $99 \mathrm{~mm}$ for eight cycles and $98.5 \mathrm{~mm}$ for four cycles. In comparison, the ECG signal calibration obtained the measurement results of $10 \mathrm{~mm}$ and still within the tolerance limit of 5\%. The calibration results of the sinusoidal signal $20 \mathrm{~mm}$ and even within the tolerance limit of $10 \%$.
\end{abstract}

Key Words : ECG, calibration, tolerance values

\section{PENDAHULUAN}

Jantung merupakan organ tubuh yang sangat vital dan mempunyai peran penting bagi kehidupan seseorang. Setiap denyut jantung dibentuk oleh gerakan impuls listrik dari dalam otot jantung. Oleh Karena itu penting bagi seorang pasien untuk melakukan pemeriksaan jantung sejak dini.

Electrocardiogram (ECG) merupakan metode yang umum digunakan untuk mendiagnosa kondisi jantung seorang pasien. Komponen utama yang terdapat pada sebuah sinyal ECG adalah kompleks QRS yang menggambarkan proses depolarisasi pada ventrikel. Faktor penting pada diagnosa ini adalah pengukuran interval waktu antara puncak-puncak $R$ kompleks QRS sinyal ECG (interval RR) yang menyatakan frekuensi detak jantung [1].

Sehingga sangatlah penting untuk 
memperoleh hasil yang akurat agar dalam menentukan diagnosa penyakit seorang pasien. Tidak presisinya peralatan EKG akan menyebabkan hasil perekaman aktivitas kelistrikan jantung yang tidak akurat [2]. Dengan demikian perlu dilakukan pengujian secara berkala pada alat ECG dan dilakukan kalibrasi. Kalibrasi Electrocardiograph (ECG) bertujuan untuk menentukan kebenaran konvensional nilai penunjukan alat ukur tersebut. Manfaat kalibrasi yaitu menjaga kondisi instrumen alat ukur dan bahan ukur seperti Electrocardiograph (ECG) agar tetap sesuai dengan spesifikasinya[3], mendukung sistem mutu yang diterapkan di instansi kesehatan, juga untuk mendapatkan nilai koreksi serta ketidakpastian pembacaan dari alat ukur tersebut [4].

Dalam penelitian ini akan dilakukan pengujian pada alat Electrocardiograph (ECG) dengan merk GE, Tipe Mac 600. Guna mengetahui kelayakan alat dengan Mengkalibrasi ulang Electrocardiograph (ECG) secara rutin, serta mencatat kinerja alat dengan control chart mengingat jam penggunaannya yang cukup tinggi. Metode yang digunakan adalah metode perbandingan langsung dengan Electrocardiograph Simulator.

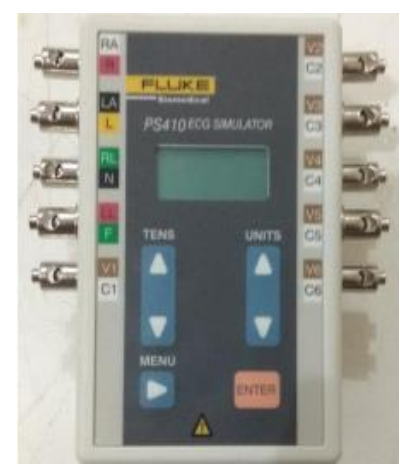

\section{Gambar 1. Fluke PS410 ECG Simulator}

\section{METODE PENELITIAN}

Pada penelitian ini dilakukan kalibrasi pada alat Electrocardiograph (ECG) dengan merk GE, Tipe Mac 600, kalibrasi dilakukan pada tanggal 22 Oktober 2020 di PT Famed Calibration.

Metode yang digunakan untuk kalibrasi Electrocardiograph (ECG) tersebut adalah metode perbandingan langsung dengan Electrocardiograph Simulator [5]. Kalibrasi dilakukan pada kondisi lingkungan $25^{\circ} \mathrm{C} \pm 5^{\circ} \mathrm{C}$ untuk suhu ruangan dan $55 \% \mathrm{RH} \pm 20 \% \mathrm{RH}$ untuk kelembaban udara didalam ruangan.

Untuk melakukan kalibrasi dalam penelitian ini diperlukan beberapa tahapan pengujian yaitu, pengamatan visual, kalibrasi terhadap level tegangan atau amplitude, kalibrasi terhadap laju rekaman, kalibrasi pada sinyal sinusoidal dan juga pada sinyal ECG[6] [7].

Adapun metode dalam penelitian ini ditampilkan dalam flowchart sebagai berikut:

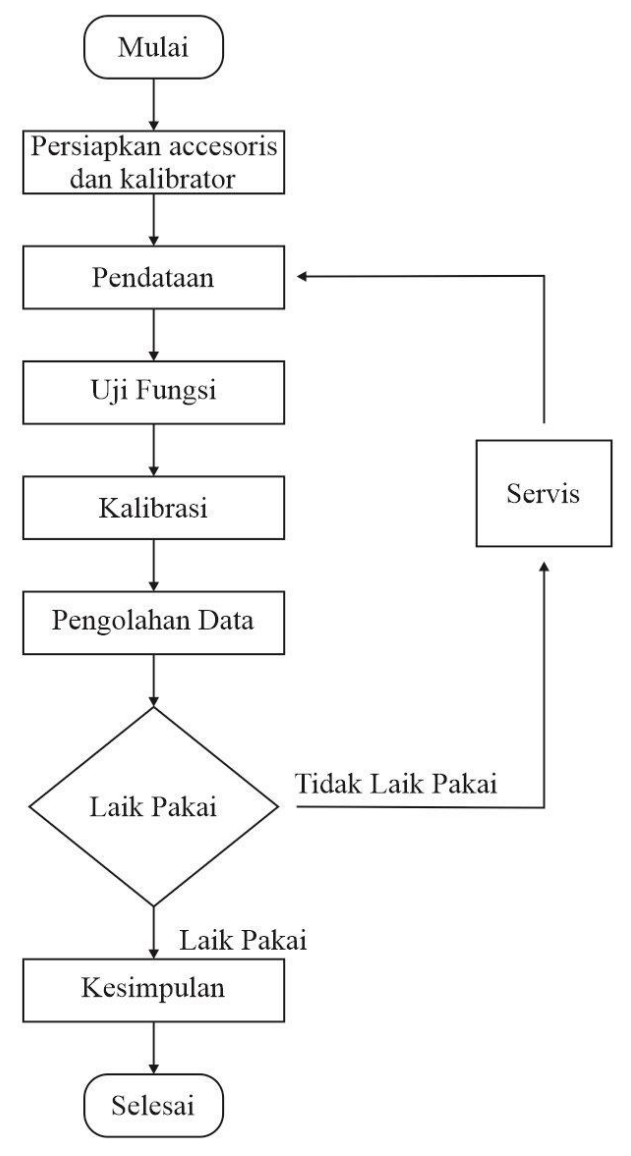

Gambar 2. Diagram alir penelitian 


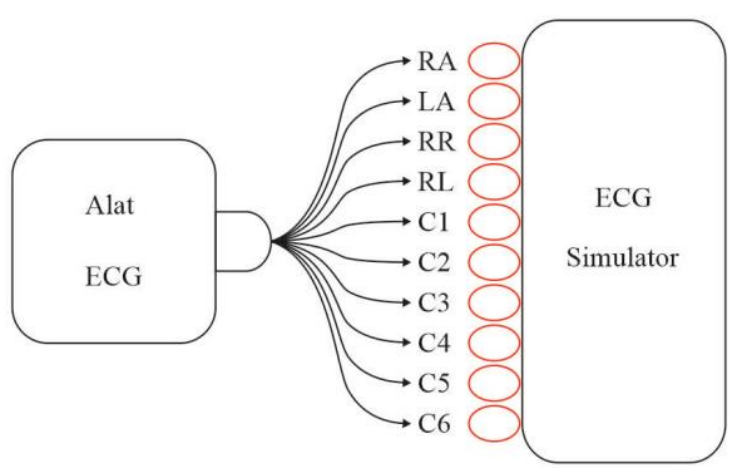

Gambar 3. lowchart Kalibrasi Elektrocardiograph

Metode perhitungan model secara matematis kalibrasi Laju Rekaman / kecepatan kertas (V)

Dimana,

$$
\mathrm{C}=1_{\text {std }}-1_{\text {uut }}-1_{\text {drift std }}
$$

C : Koreksi penunjukkan kecepatan pada alat yang di ukur (UUT)

$1_{\text {std }} \quad$ : Nilai panjang pada alat standard

$1_{\text {uut }}$ : Nilai panjang pada alat yang diukur (UUT)

$1_{\text {drift }} \quad$ : drift standard

Untuk melakukan Analisa Perhitungan ketidakpastian perlu diketahui terlebih dahulu mengenai sumber ketidakpastian, koefisien sensitifitasnya didapatkan dari model matematis diatas, dimana model matematis tersebut mempunya nilai turunan pertama yaitu 1, juga mengenai derajat kebebasan pada masing-masing sumber ketidakpastian Tipe B dengan ditentukan nilai reliabilitasnya 10 adalah $=$ 50, Menghitung ketidakpastian gabungan, derajat kebebasan efektif dan ketidakpastian bentangan.

\section{Tabel 1 Uncertainty Budget Amplitudo}

\begin{tabular}{|c|c|c|c|c|c|}
\hline No. & Komponen & Satuan & $\mathrm{U}$ & Pembagi & $U_{\mathrm{i}}$ \\
\hline 1. & Pengukuran Berulang & $\mathrm{Mm}$ & $\partial$ & $\sqrt{n}$ & $\frac{\partial}{\sqrt{n}}$ \\
\hline 2. & Sertifikat Mistar & $\mathrm{Mm}$ & $\mathrm{U}_{\text {Sertf stand2 }}$ & $\mathrm{K}$ & $\frac{U_{\text {Sertfstd }}}{\mathrm{K}}$ \\
\hline 3. & Drift Mistar & $\mathrm{Mm}$ & $\mathrm{U}_{\text {drif2 } 2}$ & $\sqrt{3}$ & $\frac{U_{\text {drift }}}{\sqrt{3}}$ \\
\hline 4. & Resolusi Alat & $\mathrm{Mm}$ & $\mathrm{U}_{\text {resolusi }}$ & $\sqrt{3}$ & $\frac{U_{\text {res }}}{\sqrt{3}}$ \\
\hline
\end{tabular}

Tabel 2. Uncertainty Budget Laju Rekam

\begin{tabular}{|c|c|c|c|c|c|}
\hline No. & Komponen & Satuan & $\mathrm{U}$ & Pembagi & $U_{\mathrm{i}}$ \\
\hline 1. & $\begin{array}{c}\text { Pengukuran } \\
\text { Berulang }\end{array}$ & $\mathrm{Mm}$ & $\partial$ & $\sqrt{n}$ & $\frac{\partial}{\sqrt{n}}$ \\
\hline 2. & Sertifikat Mistar & $\mathrm{Mm}$ & $\mathrm{U}_{\text {Sert stand2 }}$ & $\mathrm{K}$ & $\frac{U_{\text {Sertfstd }}}{\mathrm{K}}$ \\
\hline 3. & Drift Mistar & $\mathrm{Mm}$ & $\mathrm{U}_{\text {drift2 }}$ & $\sqrt{3}$ & $\frac{U_{\text {drift }}}{\sqrt{3}}$ \\
\hline 4. & Resolusi Alat & $\mathrm{Mm}$ & $\mathrm{U}_{\text {resolusi }}$ & $\sqrt{3}$ & $\frac{U_{\text {res }}}{\sqrt{3}}$ \\
\hline
\end{tabular}

Tabel 3. Uncertainty Budget Sinyal Sinusoida dan Impuls

\begin{tabular}{|c|c|c|c|c|c|}
\hline No. & Komponen & Satuan & $\mathrm{U}$ & Pembagi & $U_{\mathrm{i}}$ \\
\hline 1. & $\begin{array}{c}\text { Pengukuran } \\
\text { Berulang }\end{array}$ & $\mathrm{Mm}$ & $\partial$ & $\sqrt{n}$ & $\frac{\partial}{\sqrt{n}}$ \\
\hline 2. & Sertifikat Mistar & $\mathrm{Mm}$ & $\mathrm{U}_{\text {Sertf stand2 }}$ & $\mathrm{K}$ & $\frac{U_{\text {Sertfstd }}}{\mathrm{K}}$ \\
\hline 3. & Drift Mistar & $\mathrm{Mm}$ & $\mathrm{U}_{\text {drif2 } 2}$ & $\sqrt{3}$ & $\frac{U_{\text {drift }}}{\sqrt{3}}$ \\
\hline 4. & Resolusi Alat & $\mathrm{Mm}$ & $\mathrm{U}_{\text {resolusi }}$ & $\sqrt{3}$ & $\frac{U_{\text {res }}}{\sqrt{3}}$ \\
\hline
\end{tabular}

Pengerjaan dilakukan sesuai prosedur mutu yang telah ditetapkan pada metode kerja [8], kemudian lembar kerja kalibrasi yang berisi data mentah diperiksa oleh bagian Litbang lalu dilakukan proses pelaporan di bagian sertifikat. Proses pelaporan dilakukan dengan menghitung data pada dokumen excel yang telah tersedia yang disebut Budget Ketidakpastian (BK). BK tersebut berisi perhitungan kalibrasi yang dibuat oleh bagian Litbang sesuai metode dan acuan yang telah ditetapkan PT Famed Calibration, kemudian di verifikasi oleh petugas yang berwenang dan digunakan untuk keperluan perhitungan hasil kalibrasi. Setelah pelaporan selesai dibuat, maka bagian sertifikat akan mengeluarkan Sertifikat Laik atau tidaknya alat Ukur yang telah dikalibasi tersebut.

\section{HASIL DAN PEMBAHASAN}

Berdasarkan hasil kalibrasi pada alat Electrocardiograph (ECG) dengan merk GE, Tipe Mac 600, kalibrasi dilakukan pada tanggal 22 Oktober 2020 ditampilkan pada Tabel 4 s/d Tabel 9 berikut ini:

Tabel 4. Pengamatan Visual

\begin{tabular}{ccccc}
\hline $\begin{array}{c}\text { Paper Speed } \\
\text { UUT }(\mathrm{mm} / \mathrm{s})\end{array}$ & $\begin{array}{c}\text { Setting pada } \\
\text { Simulator }\end{array}$ & Parameter & Hasil Visual & Batasan \\
\hline 25 & $60 \mathrm{bpm}$ & $\begin{array}{c}\text { Output Sinyal } \\
\text { 12 Lead }\end{array}$ & Baik & $\begin{array}{c}\text { Semua Chanel } \\
\text { terlihat jelas dan } \\
\text { tidak terjadi vibrasi }\end{array}$ \\
\hline
\end{tabular}


Pada Tabel 4 merupakan pengamatan hasil kalibrasi secara langsung atau data mentah dari pembacaan langsung pada parameter pengamatan visual. Berdasarkan hasil menunjukkan bahwa secara visual memiliki hasil yang baik dan terlihat jelas serta tidak ada vibrasi. Kemudian untuk hasil kalibrasi level tegangan/amplitudo ditunjukkan pada Tabel 5, pengukuran dilakukan sebanyak 3 kali, dengan nilai toleransi $\pm 5 \%$ pada masing-masing pengukuran.

\section{Tabel 5. Kalibrasi Level Tegangan/Amplitudo}

\begin{tabular}{|c|c|c|c|c|c|c|c|c|}
\hline \multirow{2}{*}{$\begin{array}{c}\text { Paper } \\
\text { Speed } \\
\text { UUT } \\
(\mathrm{mm} / \mathrm{s})\end{array}$} & \multirow{2}{*}{$\begin{array}{c}\text { Sensitivitas } \\
\text { UUT } \\
\text { (mm/mV) }\end{array}$} & \multirow{2}{*}{$\begin{array}{c}\text { Setting } \\
\text { Standar } \\
(\mathrm{Hz})\end{array}$} & \multicolumn{5}{|c|}{ Hasil Pengukuran (mm) } & \multirow[t]{2}{*}{ Toleransi $\pm 5 \%$} \\
\hline & & & I & II & III & IV & $\mathrm{v}$ & \\
\hline \multirow{3}{*}{25} & 5 & \multirow{3}{*}{2} & 5 & 5 & 5 & 5 & 5 & $4,75-5,25$ \\
\hline & 10 & & 10 & 10 & 10 & 10 & 10 & $9,5-10,5$ \\
\hline & 20 & & 20 & 20 & 20 & 20 & 20 & $19-21$ \\
\hline
\end{tabular}

Untuk hasil kalibrasi pada laju rekaman pada Tabel 6 memiliki nilai standard 100 $\mathrm{mm}$ dengan hasi pengukuran yang memiliki tolerasi $\pm 5 \%$ yaitu $95-105$ yang berarti memiliki nilai eror yang kecil.

Tabel 6. Kalibrasi Laju Rekaman

\begin{tabular}{cccccc}
\hline $\begin{array}{c}\text { Setting } \\
\text { UUT } \\
(\mathrm{mm} / \mathrm{s})\end{array}$ & $\begin{array}{c}\text { Setting } \\
\text { Pada } \\
\text { Simulator }\end{array}$ & $\begin{array}{c}\text { Panjang } \\
\text { Siklus }\end{array}$ & $\begin{array}{c}\text { Nilai } \\
\text { Standar } \\
(\mathrm{mm})\end{array}$ & $\begin{array}{c}\text { Hasil } \\
\text { pengukuran } \\
(\mathrm{mm})\end{array}$ & $\begin{array}{c}\text { Toleransi } \pm \\
5 \%\end{array}$ \\
\hline 25 & $2 \mathrm{mV}, 120$ & 8 & 100 & 99 & $95-105$ \\
50 & $\mathrm{bpm}$ & 4 & & 98,5 & \\
\hline
\end{tabular}

Pada kalibrasi sinyal sinusoidal (Tabel 7) juga memiliki hasil pengukuran yang cukup akurat dengan batas toleransi $\pm 10 \%$ yaitu dengan nilai standard 20 dan hasil pengukurannya adalah sebesar 20

Tabel 7. Kalibrasi Sinyal Sinusoidal

\begin{tabular}{|c|c|c|c|c|c|c|}
\hline \multicolumn{2}{|c|}{ Setting Simulator } & \multirow{2}{*}{$\begin{array}{l}\text { Setting } \\
\text { UUT }\end{array}$} & \multirow{2}{*}{$\begin{array}{l}\text { Jumlah } \\
\text { Siklus }\end{array}$} & \multirow{2}{*}{$\begin{array}{c}\text { Nilai } \\
\text { standar } \\
\text { tinggi pulsa } \\
(\mathrm{mm})\end{array}$} & \multirow{2}{*}{$\begin{array}{c}\text { Hasil } \\
\text { Pengukuran }\end{array}$} & \multirow{2}{*}{$\begin{array}{c}\text { Toleransi } \\
\pm 10 \% \\
(\mathrm{~mm})\end{array}$} \\
\hline $\begin{array}{l}\text { Frekuensi } \\
(\mathrm{Hz})\end{array}$ & $\underset{(\mathrm{mV})}{\text { Amplitudo }}$ & & & & & \\
\hline 10 & 1 & $\begin{array}{c}\text { Gain : } \\
20 \\
\mathrm{mV} / \mathrm{mm} \\
\text { Kec. } \\
\text { Kertas : } \\
25 \mathrm{~mm} / \mathrm{s}\end{array}$ & 5 & 20 & 20 & $19-21$ \\
\hline
\end{tabular}

Untuk tabel 8 merupakan hasil kalibrasi pada sinyal ECG dengan nilai toleransi \pm $5 \%$

Tabel 8. Kalibrasi Sinyal ECG

\begin{tabular}{lccc}
\hline ECG Simulator & Gain ECG & $\begin{array}{c}\text { Hasil pengukuran } \\
\text { Amplitudo R-S (mm) }\end{array}$ & Toleransi (mm) \\
\hline $60 \mathrm{bpm}, 2 \mathrm{mV}$ & $10 \mathrm{~mm} / \mathrm{mV}$ & 10 & $\pm 5 \%$ \\
\hline
\end{tabular}

Berdasarkan hasil pengukuran pada Tabel 4 s/d Tabel 8 menunjukkan hasil kalibrasi memiliki nilai pengukuran yang akurat dengan toleransi pada masing-masing parameter pengukuran.

Langkah selanjutnya adalah melakukan analisis pengujian terhadap hasil kalibrasi tersebut dengn menggunakan perhitungan kalibrasi pada budget ketidakpastian pada masing-masing parameter [9].

\section{Analisis Pengujian Kalibrasi}

Berdasarkan hasil perhitungan kalibrasi pada Budget Ketidakpastian untuk tiap tahap Kalibrasi, didapatkan hasil sebagai berikut:

Tabel 9. Analisis Hasil Kalibrasi Level Tegangan

\begin{tabular}{ccccc}
\hline $\begin{array}{c}\text { Setting UUT } \\
(\mathrm{mm} / \mathrm{mV})\end{array}$ & $\begin{array}{c}\text { Hasil } \\
\text { Pengukuran } \\
(\mathrm{mm} / \mathrm{mV})\end{array}$ & $\begin{array}{c}\text { Hasil } \\
\text { koreksi } \\
(\mathrm{mm} / \mathrm{mV})\end{array}$ & Ketidakpastian & $\begin{array}{l}\text { Toleransi } \\
(\%)\end{array}$ \\
\hline 5 & 5 & 8.85 & 2.20 & $5 \%$ \\
10 & 10 & 9.84 & 2.20 & $5 \%$ \\
20 & 20 & 19.84 & 2.20 & $5 \%$ \\
\hline
\end{tabular}

Pada tabel 9 merupakan analisis hasil kalibrasi terhadap pengukuran level tegangan, dengan berpedoman pada Tabel 1 maka diperoleh ketidakpastian dari pengukuran kalibrasi level tegangan/amplitude adalah sebesar 2,20 pada masing-masing pengukuran berulang yang telah dilakukan sebanyak 3 kali.

Tabel 10. Analisis Hasil Kalibrasi Laju Rekaman

\begin{tabular}{ccccccc}
\hline $\begin{array}{c}\text { Setting } \\
\begin{array}{c}\text { UUT } \\
(\mathrm{mm} / \mathrm{ms})\end{array}\end{array}$ & $\begin{array}{c}\text { Setting } \\
\text { Standar }\end{array}$ & $\begin{array}{c}\text { Tampilan yang } \\
\text { diharapkan untuk 8 } \\
\text { dan 4 siklus }(\mathrm{mm})\end{array}$ & $\begin{array}{c}\text { Hasil } \\
\text { Pengukuran } \\
(\mathrm{mm} / \mathrm{mV})\end{array}$ & $\begin{array}{c}\text { Hasil } \\
\text { koreksi } \\
(\mathrm{mm} / \mathrm{mV})\end{array}$ & $\begin{array}{c}\text { Ketidak- } \\
\text { pastian }\end{array}$ & $\begin{array}{l}\text { Toleran } \\
\text { si }(\%)\end{array}$ \\
\hline 25 & 120 & 100 & 99 & 98,72 & 1,1 & $5 \%$ \\
50 & 120 & 98,5 & 98,29 & 1,1 & $5 \%$ \\
\hline
\end{tabular}

Untuk analisis hasil kalibrasi pada laju rekaman pada hasil pengukuran yang dilakukan sebanyak dua kali diperoleh 99 $\mathrm{mm} / \mathrm{mV}$ dan $98.5 \mathrm{~mm} / \mathrm{mV}$ dengan hasil koreksinya $\quad 98,72 \quad \mathrm{~mm} / \mathrm{mV}$ nilai ketidakpastiannya adalah sebesar 1.1. sedangkan pada Tabel 11 analisis hasil kalibrasi pada sinyal ECG dengan hasil pengukuran $10 \mathrm{~mm}$ dan hasil koreksinya $9.84 \mathrm{~mm} / \mathrm{mV}$ nilai ketidakpastian sebesar 0.68 . 
Tabel 11. Analisi Hasil kalibrasi sinyal ECG

\begin{tabular}{cccccc}
\hline $\begin{array}{c}\text { Setting } \\
\begin{array}{c}\text { UUT } \\
(\mathrm{mV})\end{array}\end{array}$ & $\begin{array}{c}\text { Gain ECG } \\
(\mathrm{mm} / \mathrm{mV})\end{array}$ & $\begin{array}{c}\text { Hasil } \\
\text { Pengukuran } \\
(\mathrm{mm})\end{array}$ & $\begin{array}{c}\text { Hasil } \\
\text { koreksi } \\
(\mathrm{mm} / \mathrm{mV})\end{array}$ & Ketidakpastian & Toleransi (\%) \\
\hline 2 & 10 & 10 & 9,84 & 0,68 & $5 \%$ \\
\hline
\end{tabular}

Pada tabel 12 merupakan analisis hasil kalibrasi pada parameter sinyal sinusoida dengan hasil pengukuran $20 \mathrm{~mm}$ dengan hasil koreksi $19.84 \mathrm{~mm} / \mathrm{Mv}$ maka ketidakpastian yang diperolehnya adalah 2.20

\section{Tabel 12. Analisis Hasil kalibrasi Sinyal} Sinusoida

\begin{tabular}{cccccc}
\hline $\begin{array}{c}\text { Frekuensi } \\
(\mathrm{Hz})\end{array}$ & $\begin{array}{c}\text { Amplitudo } \\
(\mathrm{mV})\end{array}$ & $\begin{array}{c}\text { Hasil } \\
\text { Pengukuran } \\
(\mathrm{mm})\end{array}$ & $\begin{array}{c}\text { Hasil } \\
\text { koreksi } \\
(\mathrm{mm} / \mathrm{mV})\end{array}$ & Ketidakpastian & $\begin{array}{c}\text { Toleransi } \\
(\%)\end{array}$ \\
\hline 10 & 1 & 20 & 19,84 & 2,20 & $10 \%$ \\
\hline
\end{tabular}

\section{SIMPULAN}

Berdasarkan hasil kalibrasi dan analisis ketidakpastian pada masing-masing parameter pengukuran yaitu pada kalibrasi level tegangan, laju rekaman, sinyal ECG dengan nilai toleransi $5 \%$ dan hasil kalibrasi pada sinyal sinusoidal diperoleh nilai toleransi $10 \%$, maka dapat disimpulkan bahwa alat kesehatan Electrocardiograph (ECG) tersebut dinyatakan layak pakai.

\section{DAFTAR PUSTAKA}

[1] U. Wiharja and M. I. T. Setyadi, "ANALISA KALIBRASI ELEKTROCARDIOGPH," Semin. Nas. Teknol. Fak. Univ. Krisnadwipayana, Jakarta, 2019.
[2] D. Ni Nyoman, ECG simulator. Surabaya: Politeknik Kesehatan kementrian kesehatan Surabaya, 2019.

[3] T. Istiqomah, "Rancang bangun Elektrokardiograf," no. 071211533039, pp. 22-72, 2012.

[4] A. A. Willa Olivia, "Rancang Bangun Kalibrator Elektrokardiogram," Sinusoida, vol. 19, no. 2, 2017.

[5] K. K. RI, PERMENKES RI NOMOR 54 Tentang Pengujian dan Kalibrasi Alat kesehatan. 2015.

[6] E. Setianingsih, A. S. R, and H. Fitriawan, "Rancang Bangun Kalibrator Eksternal Elektrokardiograf 3 Leads Berbasis ATMEGA8535," J. Rekayasa dan Teknol. Elektro, vol. 6, no. 2, pp. 127-140, 2012.

[7] S. Riandi Oktovian, A. Suhensi, and ., "PERANCANGAN SISTEM SIMULASI SINYAL ECG BERBASIS

MIKROKONTROLER," vol. 5, no. 3, pp. 5849-5856, 2018.

[8] M. Oktapiana, "Instruksi Kerja Pengujian dan Kalibrasi Elektrocardiograph (ECG)," Depok, 2019.

[9] I. D. G. B. Whinangun, A. Pudji, M. R. Makruf, B. Utomo, and S. Luthfiyah, "Electrocardiograph Simulator Berbasis Mikrokontroler," J. Teknokes, vol. 12, no. 1, pp. 5-13, 2019, doi: 10.35882/teknokes.v12i1.2. 